\title{
Troponina-T e Peptídeo Natriurético tipo B na COVID-19
}

\section{Troponin-T and B-Type Natriuretic Peptide in COVID-19}

\author{
Sora Yasri ${ }^{10}$ e Viroj Wiwanitkit \\ Dr. DY Patil University, Pune - Índia
}

\section{Caro Editor,}

Gostaríamos de compartilhar ideias sobre a publicação "Valor Prognóstico da Troponina T e do Peptídeo Natriurético Tipo B em Pacientes Internados por COVID-19. ${ }^{1}$ Almeida Jr. et al., ${ }^{1}$ relataram o uso da caixa de memória como uma ferramenta para apoiar o luto e concluíram que "Nas primeiras $24 \mathrm{~h}$ de admissão, TnT, mas não o BNP, foi marcador independente de mortalidade ou necessidade de ventilação mecânica invasiva. ${ }^{\prime 1} \mathrm{Na}$ COVID-19, a complicação cardíaca é possível e comum em infecções graves. ${ }^{2} \mathrm{O}$ comprometimento miocárdico é um problema cardíaco comum e a miocardite imunológica é uma importante manifestação grave da COVID-19. ${ }^{3}$ Portanto, a troponina-T, que é um bom biomarcador de lesão miocárdica, pode ter um bom fator prognóstico para a gravidade da COVID-19. No entanto, deve-se notar que problemas renais também podem induzir alterações da troponina- ${ }^{4}$ Se o paciente tiver um problema renal subjacente, a interpretação da troponina-T em pacientes com COVID-19 deve ser cuidadosa.

\section{Palavras-chave}

COVID-19/complicações; Betacoronavírus; Mortalidade; Hospitalização; Miocardite; Biomarcadores; Troponina T; Peptídeo Natriurético Tipo B.

Correspondência: Sora Yasri •

Private Academic Practice Bangkok 1-2012021 - Tailândia

E-mail: sorayasri@outlook.co.th

Artigo recebido em 09/11/2020, revisado em 16/12/2020, aceito em 16/12/2020.

DOI: https://doi.org/10.36660/abc.20201191

\section{Referências}

1. Almeida Junior GLG, Braga F, Jorge JK, Nobre GF, Kalichsztein M, Faria PMP, et al. Prognostic Value of Troponin-T and B-Type Natriuretic Peptide in Patients Hospitalized for COVID-19. Arq Bras Cardiol. 2020 Oct;115(4):660-6.

2. Guo T, Fan Y, Chen M, Wu X, Zhang L, He T, et al. Cardiovascular Implications of Fatal Outcomes of Patients With Coronavirus Disease 2019 (COVID-19). JAMA Cardiol. 2020 Jul 1;5(7):811-8
3. Kogan EA, Berezovskiy YS, Blagova OV, Kukleva AD, Bogacheva GA Kurilina EV, et al. Miocarditis in Patients with COVID-19 Confirmed by Immunohistochemical. Kardiologiia. 2020 Jun 19;60(7):4-10.

4. Bozbas H, Yildirir A, Muderrisoglu H. Cardiac enzymes, renal failure and renal transplantation. Clin Med Res. 2006 Mar;4(1):79-84. 